\title{
Tonic Dopaminergic Stimulation Impairs Associative Learning in Healthy Subjects
}

\author{
Caterina Breitenstein*,1,2,3, Catharina Korsukewitz', ${ }^{1,3}$ Agnes Flöel', Timo Kretzschmar', Kai Diederich' \\ and Stefan Knecht ${ }^{1,2}$ \\ 'Department of Neurology, University of Muenster, Muenster, Germany; ${ }^{2}$ IZKF Muenster, University of Muenster, Muenster, Germany
}

\begin{abstract}
Endogenous dopamine plays a central role in salience coding during associative learning. Administration of the dopamine precursor levodopa enhances learning in healthy subjects and stroke patients. Because levodopa increases both phasic and tonic dopaminergic neurotransmission, the critical mechanism mediating the enhancement of learning is unresolved. We here probed how selective tonic dopaminergic stimulation affects associative learning. Forty healthy subjects were trained in a novel vocabulary of 45 concrete nouns over the course of 5 consecutive training days in a prospective, randomized, double-blind, placebo-controlled design. Subjects received the tonically stimulating dopamine-receptor agonist pergolide $(0.1 \mathrm{mg})$ vs placebo 120 min before training on each training day. The dopamine agonist significantly impaired novel word learning compared to placebo. This learning decrement persisted up to the last follow-up 4 weeks post-training. Subjects treated with pergolide also showed restricted emotional responses compared to the PLACEBO group. The extent of 'flattened' affect with pergolide was related to the degree of learning inhibition. These findings suggest that tonic occupation of dopamine receptors impairs learning by competition with phasic dopamine signals. Thus, phasic signaling seems to be the critical mechanism by which dopamine enhances associative learning in healthy subjects and stroke patients.

Neuropsychopharmacology (2006) 3 I, 2552-2564. doi:I 0. I038/sj.npp. I 30I I 67; published online 26 July 2006
\end{abstract}

Keywords: stroke; aphasia; pergolide; dopamine; learning; memory

\section{INTRODUCTION}

Learning is based on adaptive changes of neuronal synaptic transmission. Synaptic strength is increased by activitydependent firing of pre- and postsynaptic neurons (Bliss and Collingridge, 1993) and neuromodulatory input, in particular by dopamine (Jay, 2003).

Dopamine is involved in different processes of memory and plasticity, operating on different receptors. Thus, dopamine is implicated in the internal reward system (Schultz, 2002) and the regulation of the prefrontal cortical circuitry underlying working memory (Castner and Goldman-Rakic, 2004; Marie and Defer, 2003). Additionally, dopamine is linked to attention and arousal-possibly through conversion of dopamine to noradrenaline (Nutt and Fellman, 1984). Protein synthesis necessary for neuronal growth and long-term memory consolidation is also influenced by dopamine (Baker et al, 2004; Gurden et al, 2000; Kandel, 2001). The functional relevance of

\footnotetext{
*Correspondence: Dr C Breitenstein, Department of Neurology, University of Münster, Albert-Schweitzer-Strasse 33, 48129 Münster, Germany, Tel: + 4925183 49969, Fax: + 49 25I 83 48I8I,

E-mail: caterina.breitenstein@uni-muenster.de

${ }^{3}$ These authors contributed equally to this work.

Received 9 February 2006; revised 8 May 2006; accepted 6 June 2006 Online publication: 12 June 2006 at http://www.acnp.org/citations/ Npp | 206060086/default.pdf
}

dopamine in memory-related processes becomes evident in pathological conditions that are associated with a decline in dopamine levels. A widely known clinical example is the working memory impairment in Parkinson's disease (Cools et al, 2002; Lewis et al, 2005; Rinne et al, 1985).

Dopamine's role in learning is additionally supported by recent findings showing that learning outcome can be improved pharmacologically by administration of the dopamine precursor levodopa. Examples are faster and better vocabulary learning (Knecht et al, 2004), increased motor training success (Floel et al, 2005b, c), and improved recovery from motor and neglect symptoms after stroke (Pahlke and Scheidtmann, 2003; Scheidtmann et al, 2001).

The as of yet unresolved question is how exactly exogenous dopamine modulates memory formation. Dopamine neurons can produce two different activity states: a slow tonic firing and phasic burst firing (Goto and Grace, 2005). Tonic dopamine levels, maintained by slow irregular cell firing, may contribute to maintaining alertness during learning (Schultz, 1994) and working memory functions (Goldman-Rakic et al, 2000). Phasic dopamine release signals novelty, reward prediction, and stimulus salience (Fiorillo et al, 2003; Schultz, 1997, 2002; Waelti et al, 2001). Either of these two mechanisms could mediate enhanced learning and long-term memory consolidation. One way to address the issue is to compare the effects of levodopa-which affects both tonic and phasic 
dopamine transmission - to substances that influence only one of the two (tonic vs phasic) dopamine transmission pathways.

Levodopa is taken up by dopamine neurons, converted to dopamine, packaged into vesicles, and released into the synaptic cleft in a stimulation-dependent manner (Robinson et al, 2005). Its administration may thus affect both tonic and phasic dopaminergic processes. Similar effects on dopaminergic transmission may apply to D-amphetamine, which also increases the endogenous availability of presynaptic dopamine, enhances the phasic properties of endogenous dopamine neurotransmission (Sulzer et al, 2005), and improves learning (Breitenstein et al, 2004b).

Conversely, dopamine agonists like pergolide are not taken up by dopamine neurons and therefore do not increase the presynaptic availability of dopamine. These substances thus do not have the potential to boost phasic dopamine signals. Positron emission tomography tracer studies show that direct dopaminergic agents competitively bind to dopamine postsynaptic receptors (Schreckenberger et al, 2004). They are not taken up into presynaptic dopaminergic vesicels to be phasically released 'on demand'. Thus, dopamine agonists directly act on postsynaptic dopamine receptors (Jaber et al, 1996; Koller and Rueda, 1998), thereby changing the tonic state of dopamine neurons and reducing the effects of phasic, signal-dependent endogenous dopamine release.

Some attempts have already been made to assess the potential of dopamine agonists - with variable affinity to D1- or D2-like receptors - for learning enhancement outside the realm of Parkinson's disease. However, research in healthy humans has so far failed to clearly elucidate the effects of dopamine agonist administration on cognitive performance (Ellis et al, 2005). Some studies with the selective D2-like receptor agonist bromocriptine yielded positive results on memory performance (Luciana et al, 1998; Mehta et al, 2001), whereas others failed to find an effect (Bartholomeusz et al, 2003; Kimberg et al, 1997; Muller et al, 1998) or even reported negative effects on cognition (Gibbs and D'Esposito, 2005). Considering the predominance of D1-like dopamine receptors in learningcritical structures like the hippocampus and the prefrontal cortex, one would expect a greater potential of D1-like receptor agonists in learning modulation (Jay, 2003). However, to this end, selective D1 agonists have a low bioavailability in humans and have only been used experimentally in a few clinical studies so far (Haney et al, 1999; Rascol et al, 2001). Their effects on cognition have not been examined as of now.

Results for the mixed D1/D2-like receptor dopamine agonist pergolide are inconsistent as well: pergolide improved working memory in one study (Muller et al, 1998), was effective only in a subgroup of the studied sample (Kimberg and D'Esposito, 2003), or proved ineffective (Bartholomeusz et al, 2003; Roesch-Ely et al, 2005). Even under conditions of endogenous dopamine depletion via tyrosine/phenylalanine depletion, a deterioration of working memory performance was observed after pergolide administration (Ellis et al, 2005).

One explanation for the inconsistency of effects produced by dopamine agonist administration may be the dosing scheme. As all the studies with healthy subjects so far probed the effects of a single dose of the respective dopamine agonist, the plasma levels may have been insufficient to produce consistent behavioral effects. A more promising strategy may be the repeated administration of dopamine agonists in conjunction with associative training over several days. There is preliminary evidence from several uncontrolled trials with stroke patients that verbal fluency can be improved in nonfluent aphasics after several weeks of bromocriptine administration in combination with language training (Bragoni et al, 2000; Gold et al, 2000; Gupta and Mlcoch, 1992; Sabe et al, 1992). This positive trend could not be replicated in two randomized clinical trials on bromocriptine (Gupta et al, 1995; Sabe et al, 1995). However, the latter clinical trials did not comprise parallel behavioral training, which may be a requirement for adjuvant dopaminergic therapy success (Korsukewitz et al, 2006). Thus, the potential of dopamine agonist treatment-by increasing tonic dopamine transmission levels - in enhancing learning and recovery remains controversial.

Our aim was to clarify the learning modulation potential of dopamine agonists. To this end, we chose the mixed D1/ D2-like dopamine receptor agonist pergolide and combined the pharmacological substance with an intensive associative language training in healthy subjects. The training design was highly similar to an earlier study of ours showing improved vocabulary acquisition and retention after levodopa administration in a comparable sample of young healthy subjects (Knecht et al, 2004). This allowed us to compare the effects of a selective increase in tonic dopamine signaling (through a dopamine agonist) with the increase in phasic dopamine signaling provided by levodopa administration. If the dopamine agonist proves ineffective in learning enhancement, phasic changes in dopamine transmission may be required to improve learning success. On the other hand, positive results on learning after dopamine agonist administration would provide the foundation for future studies to improve functional outcome in neurological conditions requiring (re-)learning, for example, after stroke. From a clinical point of view, dopamine agonists are preferred over levodopa because they better tolerated when taken for extended time periods in Parkinson's disease (Curran and Perry, 2004) and to have less adverse effects like dyskinesias, psychosis, or hyperhomocysteinemia, a risk factor for cardiovascular disease and dementia (Jankovic, 2002; Miller et al, 2003; Rogers et al, 2003; Seshadri et al, 2002).

\section{METHODS}

\section{Subjects}

A total of 40 healthy subjects (age range: 20-34 years) participated in this prospective, randomized, double-blind, placebo-controlled trial. The PERGOLIDE group $(n=20$, five females) was administered $0.1 \mathrm{mg}$ pergolide $120 \mathrm{~min}$ before language training on each of the 5 training days. The dose of $0.1 \mathrm{mg}$ per day was selected based on prior studies showing positive effects of a single dose of pergolide on cognition (Kimberg and D'Esposito, 2003; Muller et al, 1998). A third study using a lower dose $(0.05 \mathrm{mg})$ had no effect on cognitive performance (Bartholomeusz et al, 
2003). The PLACEBO group ( $n=20$, five females) received a standard placebo substance ( $99.5 \%$ mannitol, $0.5 \%$ erosil) in identical capsules. To prevent nausea, a common side effect of pergolide, both groups received $20 \mathrm{mg}$ of the peripheral D2-dopamine receptor antagonist domperidone 30 min before the intake of study medication on each day. In our prior study with levodopa (Knecht et al, 2004), the language training started already $90 \mathrm{~min}$ after intake of the study medication because levodopa reaches its peak plasma level earlier than pergolide $(30-60 \mathrm{~min}$ as compared to 60-120 min). Another modification to our earlier study was the addition of domperidone because of the well-known clinical problem of intense nausea after dopamine agonist ingestion.

All participants had at least 10 years of formal education and were native German speakers. Subjects were righthanded as assessed by the Edinburgh Handedness Inventory (Oldfield, 1971) and left hemisphere dominant for language as assessed by transcranial Doppler sonography (Deppe et al, 2004).

Exclusion criteria comprised bilingualism, a history of neurological, psychiatric, or medical diseases, acute infections, intake of medications affecting the central nervous system, recent consumption of recreational drugs as assessed by urinary drug screening, smoking $>10$ cigarettes/day or drinking $>6$ cups of coffee/day or $>50 \mathrm{~g}$ alcohol (equivalent of two glasses of wine) consumption/ day. To control for acute effects of caffeine and nicotine and to ensure comparable absorption of the study medication across subjects, participants were asked not to smoke, eat, or drink caffeine-containing drinks during the $2 \mathrm{~h}$ before intake of study medication. For the female participants, a pregnancy test was performed on training days 1 and 5 (negative in all cases).

Subjects' written informed consent was obtained according to the declaration of Helsinki. The Ethical Committee of the University of Münster had approved the study.

A comprehensive battery of neuropsychological tests was administered to all subjects in a separate session before language training, comprising tests of general intellectual functioning, attention, verbal fluency, digit spans, verbal and visuospatial memory, and personality scales (see Table 1). These background measures served to ensure maximal comparability of the two groups with respect to baseline cognitive functions and personality factors.

\section{Experimental Design}

The vocabulary training program has been described in detail elsewhere (Breitenstein and Knecht, 2002) and has been employed in several recent studies of our group (Breitenstein et al, 2004a, b, 2005; Knecht et al, 2004). In short, the language training is based on an associative learning principle, which involves higher cooccurrences of 'correct' arbitrary object and novel word pairings compared to 'incorrect' pairings (Breitenstein and Knecht, 2002). For example, over the course of the 5 study days, each novel word (eg /binu/) appears 20 times with the same picture (eg a tree) and only twice with each of the 10 varying pictures (eg car, broom, trumpet, cactus). An example of the frequency scheme is displayed in Figure 1. There are a total of 1800 training trials ( 5 days $\times 2$ blocks $\times 180$ trials) for each subject. Each block lasted for about 9 min with a break of 5 min between blocks on a given day. On a given trial, a picture was presented $200 \mathrm{~ms}$ after the onset of the auditory presentation of a novel word (pseudoword, all normalized to a duration of $600 \mathrm{~ms}$ ). Picture presentation lasted for $1 \mathrm{~s}$, during which subjects were asked to press one of the two keys on a response pad to indicate whether the pairing was correct or not. Response hand (left or right) was randomized across subjects. Subjects were told to intuitively decide if objects and novel words match or not. They were furthermore told that only responses occurring in the $1 \mathrm{~s}$ interval of picture presentation were accepted. The intertrial interval was limited to $1 \mathrm{~s}$ to prevent subjects from reflecting on their responses. Subjects were not informed about the underlying frequency principle.

On training day 5 , immediately after the regular training session, subjects' ability to translate the novel words into German was tested (transfer test). During this transfer test (one block with 180 trials), German object names were acoustically presented in pairs with spoken pseudowords and subjects had to decide whether the pairing was correct or not. Retention of the novel vocabulary was examined 1 week and 1 month after the last training day.

To assess general motor arousal effects of pergolide, subjects also performed a simple motor reaction task with 100 trials before each language training. The task consisted of pressing a button as quickly as possible after a tone was presented.

To determine cardiovascular effects, blood pressure and heart rate were measured every $30 \mathrm{~min}$, starting with the administration of the study medication (sample 1 at $0 \mathrm{~min}$ ) and ending with training completion (sample 6 at $150 \mathrm{~min}$ ). To assess drug effects on motivation and mood, subjects rated their feelings using the Positive and Negative Affective Schedule (PANAS) (Watson et al, 1988) every $30 \mathrm{~min}$ (same time points as for cardiovascular measures). The PANAS consists of 10 positive and 10 negative items, which measure the dimensions positive affect (high score: a state of high energy; low score: sadness and lethargy) and negative affect (high score: state of distress; low score: state of calmness). Subjects were also queried about any side effects in $30 \mathrm{~min}$ intervals starting with the arrival on each training day.

\section{Data Analysis}

Group differences on neuropsychological measures were analyzed using Bonferroni-corrected unpaired $t$-tests. Training and retention data were analyzed using ANOVAs with a trend analysis on the repeated factors 'day' (training days 1-5) and 'block' (blocks 1 and 2) and the betweensubject factor 'group' (PERGOLIDE, PLACEBO). For clarity of presentation, only significant effects involving the factor 'group' are reported. Post hoc group differences were analyzed using paired or unpaired $t$-tests, as appropriate. Correlations were examined using Pearson correlation coefficients with Bonferroni-corrected levels of significance.

\section{RESULTS}

Preliminary data analyses on the baseline cognitive and personality measures revealed that the PERGOLIDE 
Table I Group Means and Standard Deviations of the Neuropsychological Background Measures and Correlation Coefficients (Pearson) with Training Success on the Novel Vocabulary

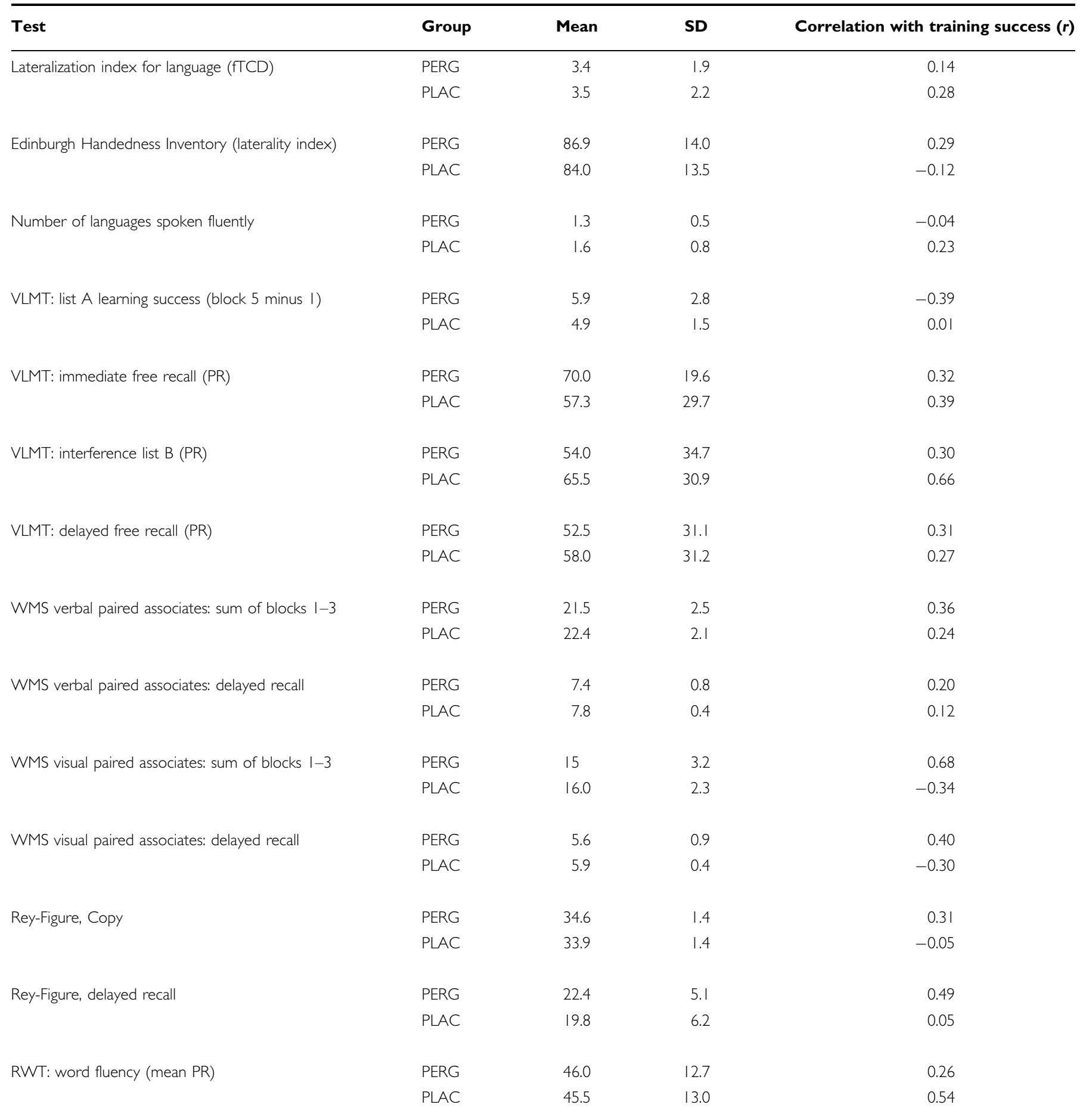

SD, standard deviation; PERG, PERGOLIDE $(n=16)$; PLAC, PLACEBO $(n=20)$; fTCD, functional transcranial Doppler sonography; VLMT, Verbaler Lern- und Merkfähigkeitstest (German version of the Rey Auditory Verbal Learning Test); RWT, Regensburger Wortflüssigkeitstest (German version of the Controlled Oral Word Association Test); WMS, Wechsler Memory Scale (German version); WAIS, Wechsler Adult Intelligence Scale (German version); Neo-FFI, German version of the Neo Five Factor Inventory; PR, percent rank; WP, Wechsler points.

group scored significantly higher in depression as compared to the PLACEBO group before training $\left(t_{(38)}=2.39, p=0.02\right)$. Because language learning success was closely related to depression scores in the PERGOLIDE group $(r=0.68, p=0.001)$, we considered it necessary to stratify the groups with respect to depression scores (range of BDI scores: 0-6) and excluded four subjects with the highest BDI scores $(\geqslant 7)$ in the PERGOLIDE group. Subsequent analyses were, therefore, conducted with $n=16$ in the PERGOLIDE group (12 men, four women). 
We would like to add in this context that the pattern of the below reported group differences did not qualitatively change with the reduced sample size.

There were no baseline group differences with respect to age, body weight (range: $60-100 \mathrm{~kg}$ ), daily consumption of nicotine and caffeine, number of languages spoken fluently, neuropsychological test scores, and personality scales (cf., Table 1). There were no serious adverse reactions to the drug. Minor side effects during the 5 training days were headaches $(n=2)$, fatigue $(n=5)$, dizziness $(n=1)$, and nausea $(n=1)$, but type or frequencies of side effects were not different for the two groups $\left(\chi^{2}=4.14, p=0.39\right)$.

Preliminary analyses had not revealed any sex differences with respect to learning rates in either group (correlations between sex and learning improvement from day 1 to 5 : both $r<|0.24|, p>0.29)$. Data were therefore pooled across sex.

\section{Language Learning}

Accuracy. Learning speed (increase in accuracy across the 5 training days) was significantly decreased in the PERGOLIDE group compared to the PLACEBO group (group $\times$ day: linear trend, $\mathrm{F}(1,34)=6.12, p=0.02$; PERGOLIDE: $\mathrm{F}(1,15)=168.52, \quad p<0.001 ; \quad$ PLACEBO: $\mathrm{F}(1,19)=361.16$, $p<0.001$ ) (cf. Figure 2). (The ANOVA for the entire sample with 40 subjects just failed to reach significance (interaction of day $\times$ group: linear trend, $\mathrm{F}(1,38)=3.30, p=0.077$ ). When the depression scores were used as a covariate, the results were identical with the presented results for the reduced sample of $n=16$ in the PERGOLIDE group (interaction of day $\times$ group: linear trend, $\mathrm{F}(1,37)=6.30$, $p=0.017)$. Group differences started to be significant on day 3 and grew increasingly larger during training days 4 and 5 (all $\left.t_{(34)}>|2.35|, p \leqslant 0.024\right)$. Both groups showed successful transfer from visual to spoken material. However, performance on the transfer test was also significantly impaired in the PERGOLIDE group compared to PLACEBO $\left.t_{(34)}=|2.55|, p=0.02\right)$.

Long-term memory retention was also significantly less in the PERGOLIDE as compared to the PLACEBO group (retention sessions 1 week and 1 month post-training: both $\left.t_{(34)}>|3.12|, p \leqslant 0.003\right)$.

There were no significant correlations between training success (performance on day 5 minus day 1) and neuropsychological background measures (see Table 1) for either group. However, the correlation between training success and depression scores yielded a trend towards significance in the PERGOLIDE group (but not in the PLACEBO group). Please note that the two groups were stratified with respect to baseline depression scores. The correlation was positive $(r=0.47, p=0.07)$, indicating that subjects with the lowest depression scores showed the greatest learning impairment under pergolide treatment (see Figure 3).

Response times. Response times during the language task decreased significantly across training days in both groups, but the decrease was significantly steeper in the PLACEBO as compared to the PERGOLIDE group (day $\times$ block $\times$ group: quadratic trend, $\mathrm{F}(1,34)=4.40, p=0.04)$. Group differences were most prominent on days 4 and 5 (both $\left.t_{(34)}>2.21, p \leqslant 0.03\right)$, with generally slower response times in the PERGOLIDE group compared to the PLACEBO group (see Figure 4). The above reported group difference in learning accuracy can therefore not be explained by group differences in accuracy-speed tradeoff.

For the retention sessions after 1 week and 1 month, there were no significant group differences in response times
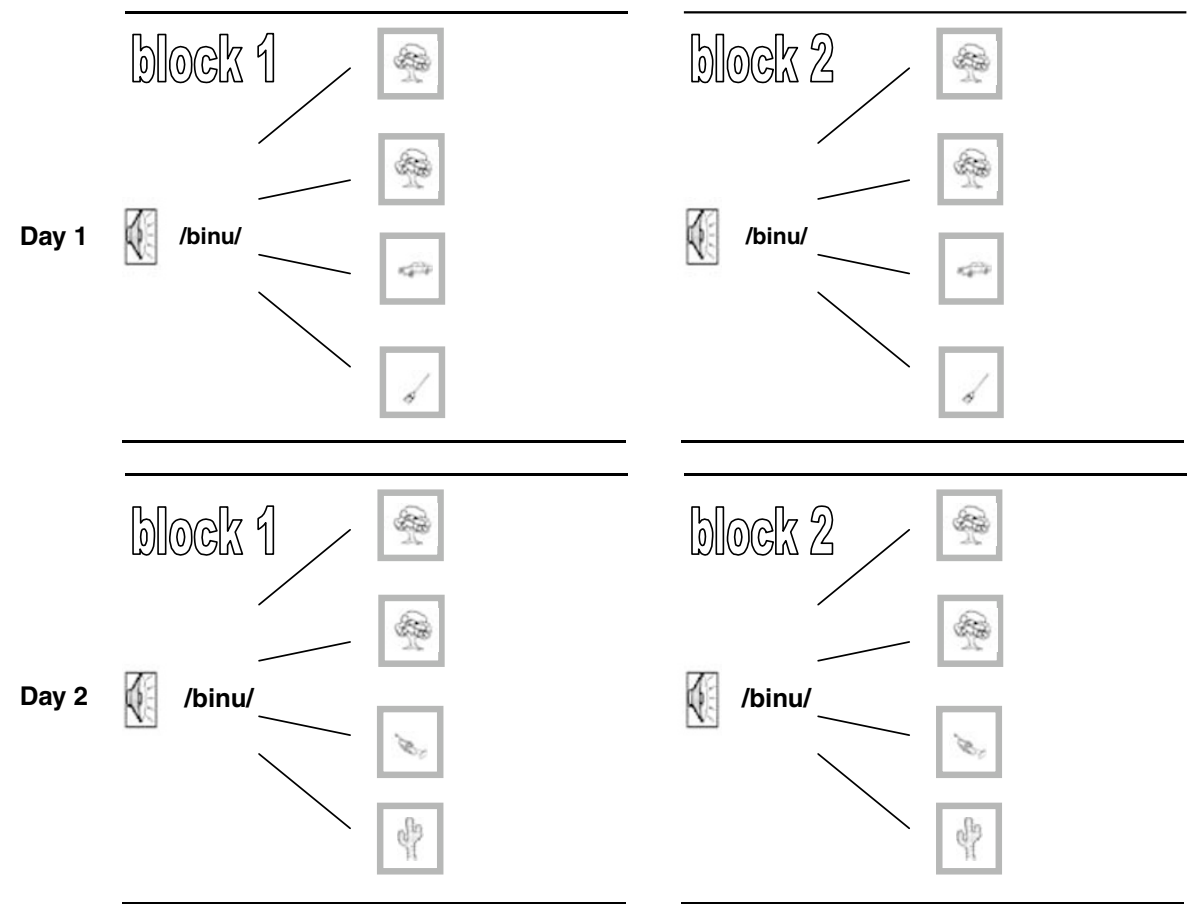

Figure I Frequency scheme of the associative learning task. On a given training day, each pseudoword (eg /binu/) appeared four times with the same object (eg a tree), but only twice with one of two different objects (car, broom). The correct pairings (/binu/ with tree) were repeated on every training day, but the two incorrect couplings varied across training days. Thus, there was a correct: incorrect ratio of 20:2 upon completion of the training. 


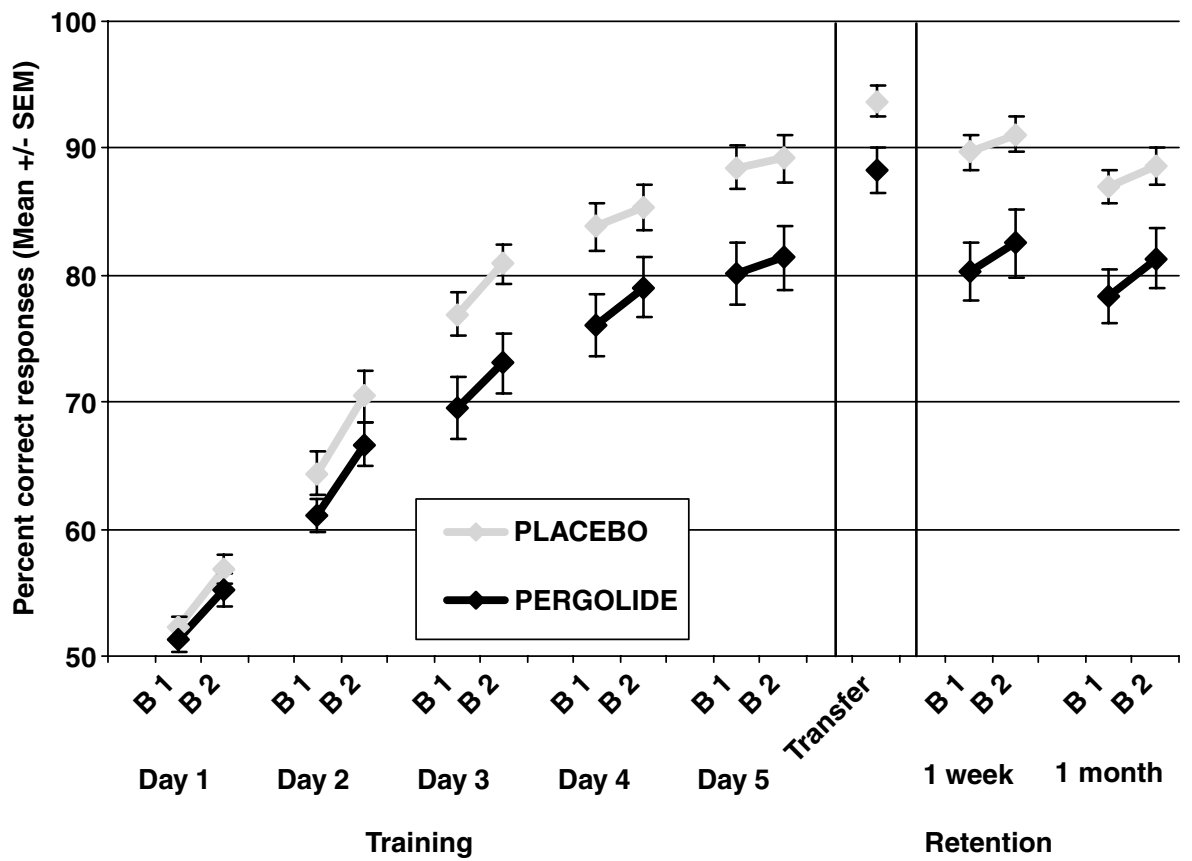

Figure 2 Mean $( \pm S E M)$ learning curves on the vocabulary learning task and performance on the transfer and retention tests of the PERGOLIDE (black) and PLACEBO (gray) groups (BI = block I, B2= block 2).
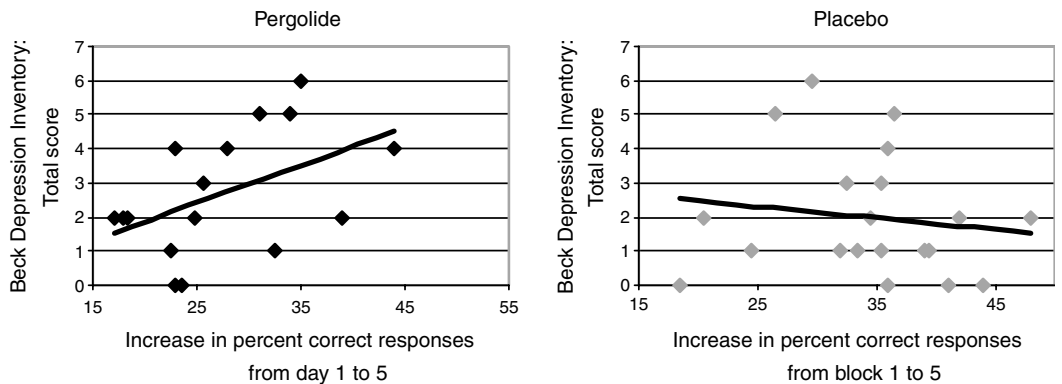

Figure 3 Correlations between baseline depression scores (BDI) and the overall learning success (increase from training day I to day 5) in acquiring a novel lexicon for the PERGOLIDE (left) and PLACEBO (right) groups. Subjects with the lowest baseline depression scores showed the smallest learning gain after administration of the dopamine agonist pergolide.

(both $p>0.17$ ). The slowed responding in the PERGOLIDE group during training was thus a medication effect and not owing to baseline group differences in response times.

\section{General Drug Arousal: Response Styles}

To determine whether the decelerated learning curves of the PERGOLIDE group could be explained with a more risky response style as part of a general drug arousal effect (eg more 'yes' responses' leading to more errors of the 'false alarm' type), subjects' responses were classified into hits, correct rejections, false alarms, and misses. (Rates of omissions were extremely low in the present study (on average less than $2 \%$ of responses and distributed equally over 'correct' and 'incorrect' trials), because the message 'time exceeded' appeared immediately on the screen if subjects did not respond within the reaction time interval of $1 \mathrm{~s}$. The experimenter sat next to the subject for the entire duration of each learning block and reminded subjects- repeatedly, if necessary - to avoid the appearance of this message. We therefore consider it extremely unlikely that slowed reaction times in the PERGOLIDE group led to a reduction of correct responses. Omissions were not included in the analyses of response types. The percent of hits, misses, correct rejections, and false alarms was calculated based on the number of valid trials for each block (total number of trials minus number of omissions).)

An ANOVA with the factors response type (4) by day (5) by group yielded a significant two-way interaction of response type $\times$ group $(\mathrm{F}(1,34)=5.31, p=0.03)$. Post hoc analyses showed no group differences for false alarms or correct rejections. However, the PERGOLIDE group produced fewer hits and more misses as compared to the PLACEBO group (both $\mathrm{F}(1,34)>3.45, p<0.07$ ), consistent with a pattern of impaired detection of salient stimuli.

\section{Motor Arousal}

Simple motor reaction times. An ANOVA with the repeated factor day (5) and the between-subject factor group 


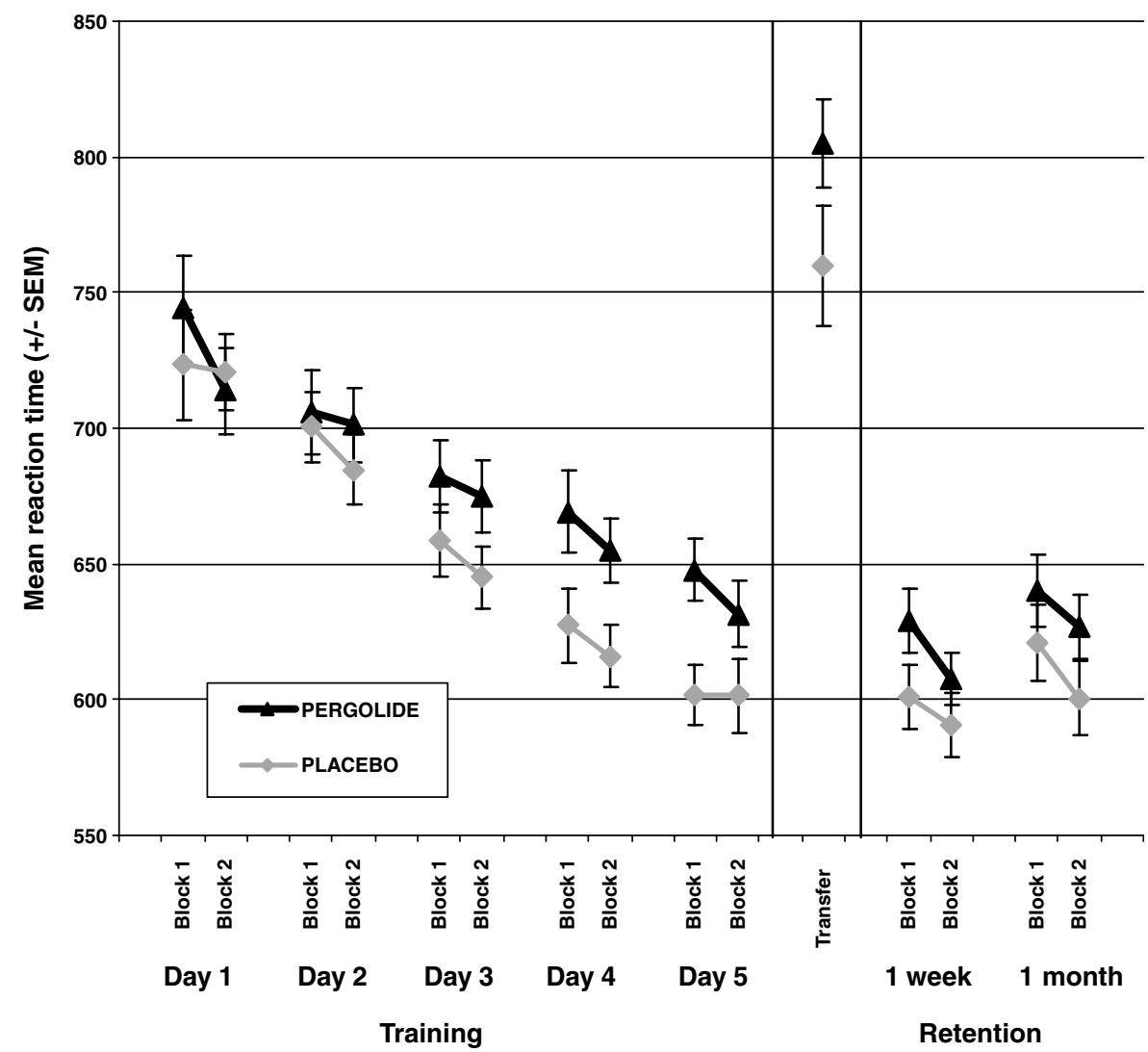

Figure 4 Mean $( \pm$ SEM) response times on the vocabulary task during the 5 training days, the transfer, and the retention sessions for the PERGOLIDE and PLACEBO groups. Please note that only trials with correct responses (hits and correct rejections) were used for data analysis.

(PERGOLIDE, PLACEBO) showed that the response times for the PLACEBO group decreased linearly from day 1 to day 5 , whereas no such change was observed in the PERGOLIDE group (day $\times$ group: linear trend, $\mathrm{F}(1,34)=$ $3.29, \quad p=0.08 ; \quad$ PERGOLIDE: $\quad \mathrm{F}(1,15)=1.55, \quad p=0.23$; PLACEBO: $\mathrm{F}(1,19=6.64, p=0.02$; cf., Figure 5).

Learning success on the novel vocabulary (accuracy on day 5 minus day 1), however, was not correlated with learning speed of the simple motor reaction time task (reaction time on day 1 minus day 5) in the PERGOLIDE group. This speaks against a sedative motor effect underlying the vocabulary learning impairment with pergolide.

No group differences were noted during the 1-week and 1 -month retention sessions (both $t_{(38)}<0.73, p>0.47$ ), reflecting the state-dependency of the inhibitory effect in the PERGOLIDE group.

\section{Cardiovascular Arousal}

Initial systolic and diastolic blood pressures, assessed approximately 1 week before language training, were not different for the two groups (systole: means of $128 \pm 3.8$ and $124.9 \pm 2.4$, respectively; diastole: means of $76.13 \pm 2.2$ and $74.75 \pm 2.1$, respectively).

ANOVAs with the repeated factors day (5) and sample within a session (6) and the between-subject factor group yielded no group differences for heart rate, systolic or diastolic blood pressure measures during the 5 training days with drug administration. The above reported group differences in learning were thus unrelated to cardiovascular measures.

\section{Mood Measures}

Positive feelings (PANAS). There were no baseline group differences in positive feelings on the first sample of day 1 before first substance ingestion.

Data for the training days were analyzed using an ANOVA with the repeated factors day (5) and sample (6) as well as the between-subject factor group. Groups differed significantly across days in their positive ratings taken within each session (day $\times$ sample $\times$ group, quadratic trend, $\mathrm{F}(1,38)=5.02, p=0.03)$. Follow-up analyses showed that positive feelings within sessions differed for the 5 training days in the PERGOLIDE group (day $\times$ sample: quadratic trend, $\mathrm{F}(1,15)=16.76, p=0.001)$, but not in the PLACEBO group. A closer inspection of the data revealed that the PLACEBO group dropped their positive mood ratings continuously within each session until the training started after $120 \mathrm{~min}$ (probably owing to boredom during the waiting period), and this pattern persisted across training days (main effect of sample: quadratic trend, $F(1,19)=$ $10.82, p=0.004)$. In the PERGOLIDE group, however, this continuous drop in positive ratings over the first $120 \mathrm{~min}$ of a session was only seen on day 1 . For training days $2-5$, positive ratings showed little fluctuation within a given session (see Figure 6). 


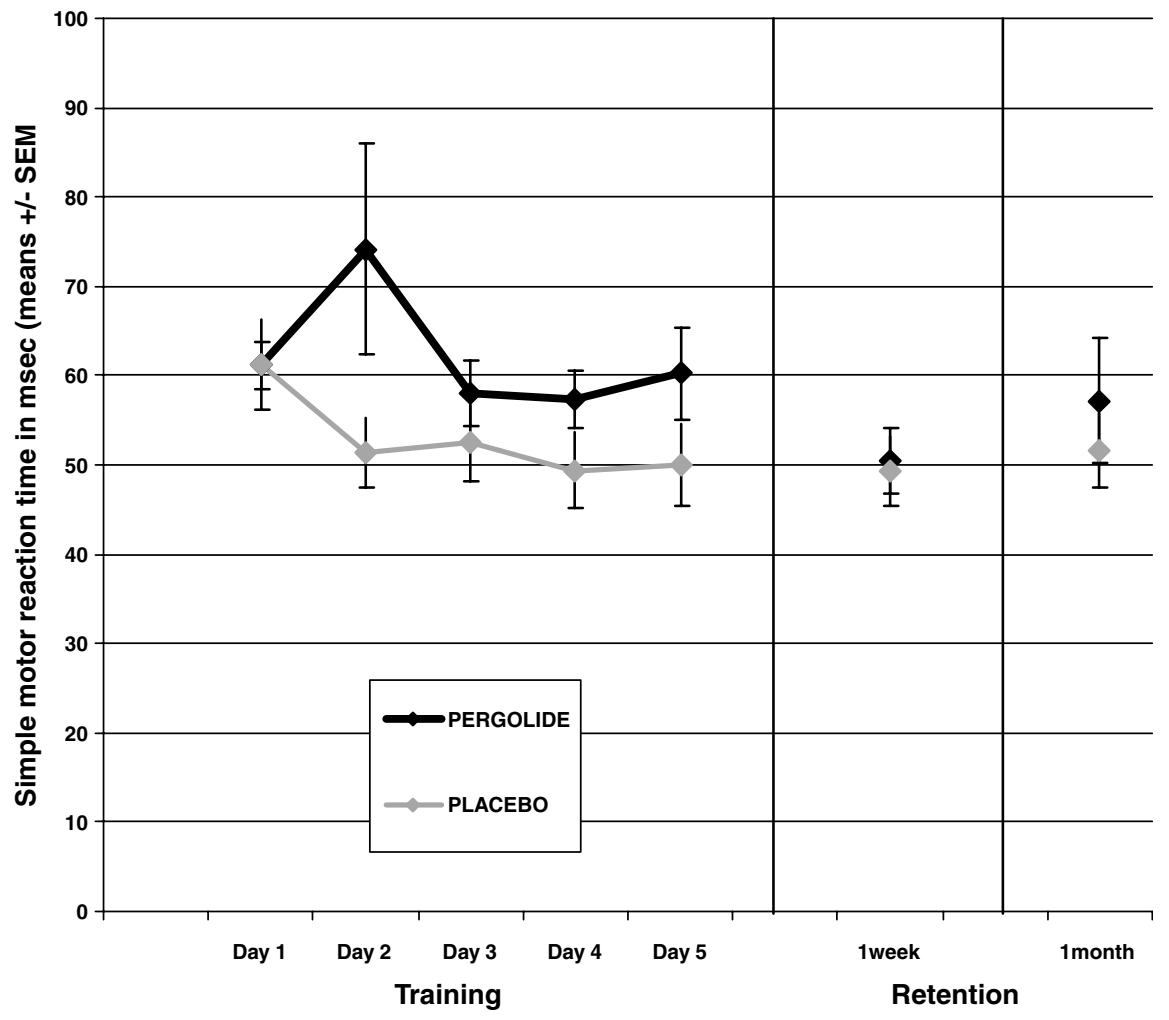

Figure 5 Mean $( \pm S E M)$ response times on the simple motor reaction time task during the 5 training days and the retention sessions for the PERGOLIDE and PLACEBO groups.

Additionally, learning success (improvement in percent of correct responses from day 1 to day 5) was positively related to the degree of mood fluctuations within a given training session (positive rating score at 0 min minus positive rating score at $120 \mathrm{~min}$; pooled over training days, respectively) in the PERGOLIDE group only: the greater the change in mood ratings within the training sessions, the greater the overall learning improvement $(r=0.36$, $p=0.17$ ). Please note that the first mood sample assessed at the beginning of each training day was not correlated with the overall learning improvement in either group. It thus seems that a 'flattened affective response', and not a general state of reduced well-being under PERGOLIDE treatment contributed to the negative drug effect on learning.

Negative feelings (PANAS). There were no baseline differences between groups on day 1 (means of $11.2 \pm 1.3$ and $11.4 \pm 1.4$ for PERGOLIDE and PLACEBO, respectively) for the negative PANAS ratings. Furthermore, no significant group differences emerged during the 5 training days (scores showed a floor effect for both groups). There was thus no indication for the induction of depressive feeling in the PERGOLIDE group.

\section{DISCUSSION}

This study demonstrates that dopamine agonist administration impairs associative learning in healthy humans. The dopamine agonist pergolide not only slowed learning across the 5 training days, but also decreased overall learning success as assessed by the retention sessions after 1 week and 1 month. Despite the lack of a correlation between slowed motor reaction times and learning rates in the PERGOLIDE group, we cannot entirely rule out an effect of motor slowing on learning performance in the PERGOLIDE group during the 5 training days. However, slowed motor performance cannot account for the poorer performance of the PERGOLIDE group during the retention sessions (without drug administration), supporting a direct inhibitory effect of pergolide on memory consolidation. Together, our findings point to a direct detrimental effect of tonic dopaminergic stimulation on associative learning.

Why did the repeated administration of pergolide - in contrast to prior findings with levodopa (Floel et al, 2005b, c; Knecht et al, 2004; Scheidtmann et al, 2001)impair learning? The most likely explanation is offered by the different pharmacological profiles of dopamine agonists and levodopa. The crucial difference is that dopamine agonists do not increase the presynaptic availability of dopamine and are thus not capable of enhancing phasic dopamine signaling. Rather, dopamine agonists exert their effect tonically on postsynaptic dopamine receptors (D1- or D2-like dopamine receptors) (Jaber et al, 1996). Additionally, they act on presynaptic D2-like dopamine autoreceptors. At least three different possible mechanisms for the inhibition of learning by pergolide must be considered: (1) Tonically increased activation (and thus receptor occupation) of postsynaptic D1- and D2-like receptors reduces the neurotransmission of phasic postsynaptic dopamine signals encoding stimulus salience. (2) Stimulation of D2-like dopamine presynaptic autoreceptors reduces dopamine release and consequently reduces phasic dopamine signal- 


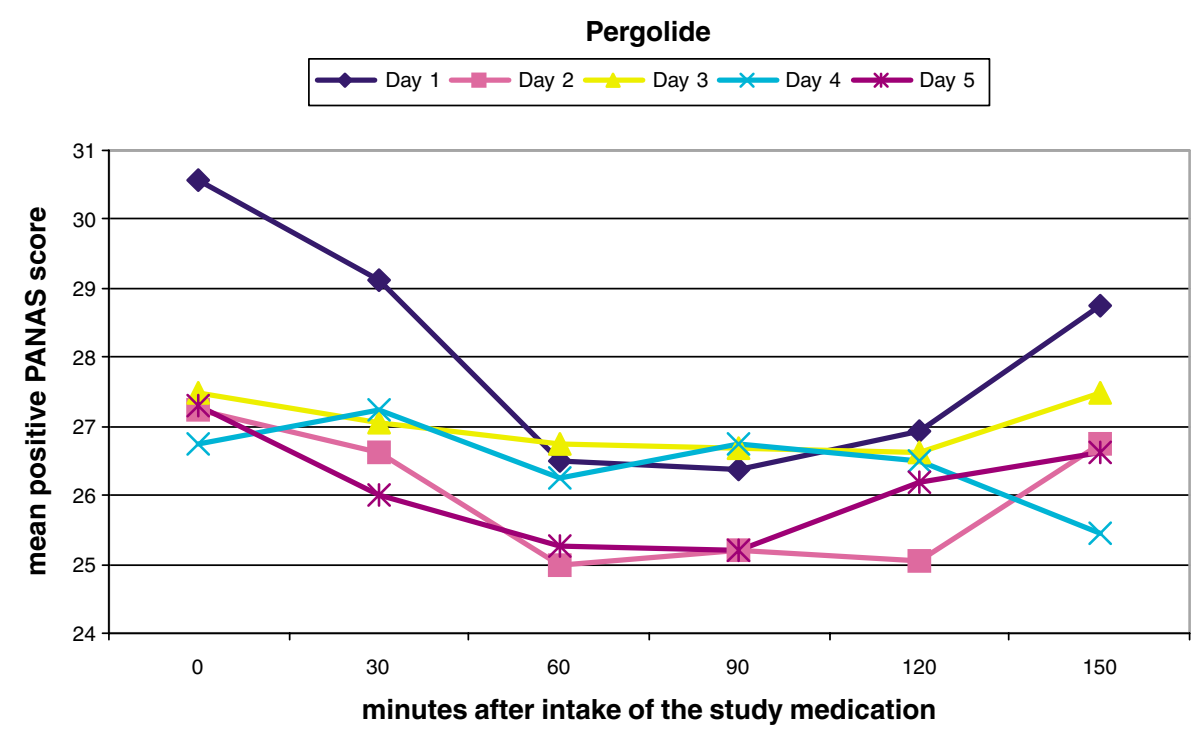

Placebo

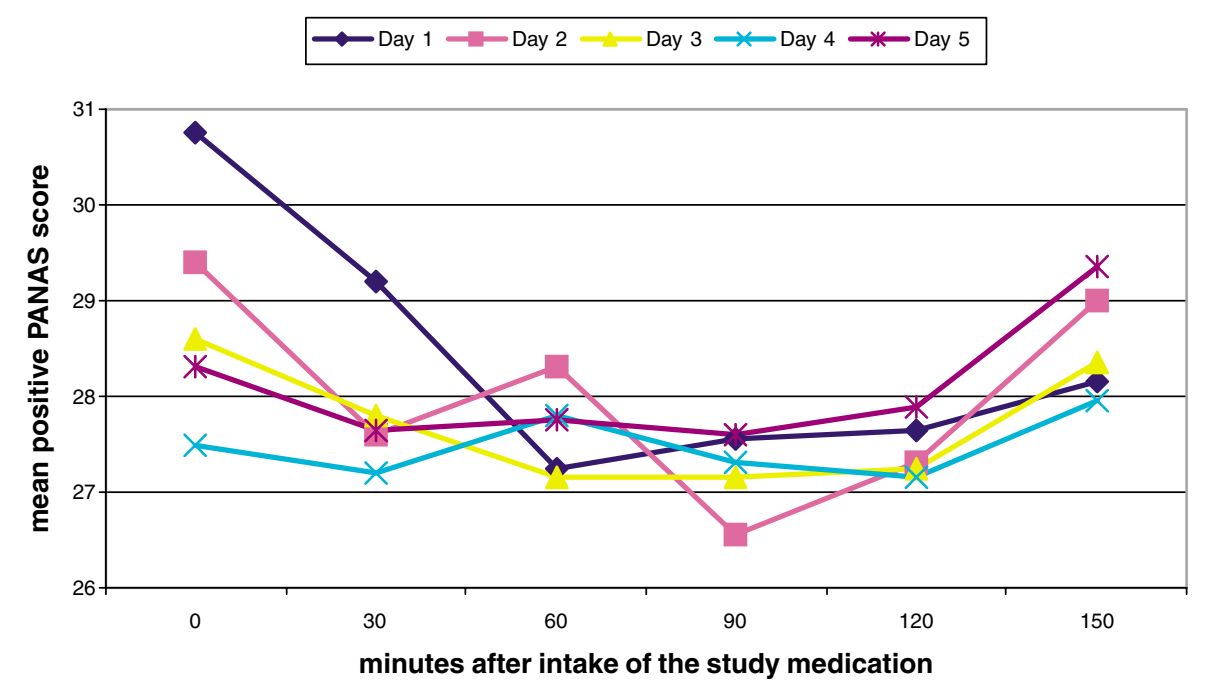

Figure 6 Mean positive PANAS ratings over the course of a given training session for the 5 training days in the PERGOLIDE (top) and PLACEBO (bottom) groups. Please note that mood changes within a given session were flattened in the PERGOLIDE group as compared to the PLACEBO group on days $2-5$.

ing. (3) Activation of D2-like receptors directly inhibits long-term potentiation (LTP) in learning-critical brain structures. We will discuss these possibilities in more detail below.

\section{Inhibition of Phasic Dopamine Signaling through Tonic Postsynaptic Receptor Occupation}

Biologically salient stimuli elicit a short latency, phasic response in midbrain dopaminergic neurons (Nieoullon, 2002; Tobler et al, 2005). The phasic coactivation of target dopamine neurons involved in the processing of a particular behavior establishes specificity of learning (Schultz, 2002). More sustained phasic release of dopamineover a period of several hundred milliseconds-occurs during periods of uncertainty about payoffs and may promote learning by allocating attention to predictors for reward (Fiorillo et al, 2003, 2004, 2005).
Substantial evidence suggests that the dynamics of phasic and tonic dopamine release in learning-critical brain structures regulate goal-oriented behaviors. Imbalances may negatively affect learning processes (Goto and Grace, 2005). It is thus feasible that under conditions of increased tonic dopamine (agonist) availability at the postsynaptic receptor, subsequent endogenous phasic dopamine release triggered by salient stimuli would elicit abnormally small neural responses in the postsynaptic neuron (Grace, 1991). Unlike levodopa, which increases presynaptic dopamine availability, dopamine agonists do not have the potential to mimic the phasic neuronal impulses required for stimulus salience coding (Schultz, 2002). The importance of phasic dopamine release for learning enhancement is further supported by recent positron emission topography findings, showing that levodopa administration predominantly increases dopamine release into the synaptic cleft during learning situations and not during rest (Antonini et al, 1994; 
Floel et al, 2005a). With respect to the associative vocabulary learning employed in our study, a pergolideinduced mitigation of the phasic dopamine signal would result in the failure to identify correct (ie salient) stimulus couplings. This is exactly what the analysis of the response styles suggests: subjects treated with pergolide had a selective deficit in detecting the correct object-word pairs (decreased number of hits and increased number of misses) as compared to the PLACEBO group. Additional evidence for a lack - or at least a reduction - of phasic dopamine signals stems from the flattening of emotional responsiveness with pergolide in the present study: whereas the PLACEBO group showed a characteristic pattern of an initial decrease in positive mood ratings during the $120 \mathrm{~min}$ waiting period-probably owing to boredom-, the PERGOLIDE group showed little mood fluctuations within a particular session on training days 2-5. This flattened emotional responsiveness in the PERGOLIDE group was furthermore correlated with the degree of learning impairment. This indicates that both phenomena (learning impairment, flattening of emotional responses) are mediated by the same underlying mechanisms, namely a reduction of phasic dopamine signals.

\section{Modulation of Learning Rates Relative to Baseline Dopamine Transmission Levels}

Another aspect of our findings deserves discussion. The PERGOLIDE and PLACEBO groups were post hoc analyzed for depression scores. Selectively for the PERGOLIDE group, subjects with greater (albeit not clinically relevant) baseline depression scores showed the least learning impairment under pergolide. The precise role played by dopamine in depression is not yet understood, but a deficient dopaminergic transmission seems to be one of the factors contributing to the symptoms of anhedonia (Dailly et al, 2004). With respect to our results, this would imply that subjects with less depressive mood-and hence higher baseline dopamine transmission rates-were more adversely affected by the administration of a dopamineagonistic substance as compared to subjects with lower baseline dopamine transmission rates. This finding is in line with previous studies showing that the behavioral effects of extrinsic dopaminergic modulation are dependent on subjects' presumed baseline prefrontal dopaminergic levels. In healthy humans, only subjects with high as compared to low baseline (prefrontal) dopaminergic functioning performed worse in a working memory task after administration of a D2-receptor dopamine agonist (Bitsios et al, 2005; Gibbs and D'Esposito, 2005; Kimberg et al, 1997) or Damphetamine (Mattay et al, 2003). Conversely, de novo patients with Parkinson's disease suffering from decreased dopamine levels improved on learning tasks after treatment with pergolide (Kulisevsky et al, 2000), consistent with other findings that a tonic hypodopaminergic condition is associated with decreased efficiency of prefrontal cortical information processing in Parkinson's disease (Mattay et al, 2002). This underscores the beneficial potential of dopamine agonists on cognitive processes in hypodopaminergic conditions like Parkinson's disease, possibly by improving tonic functions like attention or working memory.
The discrepancy between our findings and those of other groups studying the cognitive effects of pergolide in healthy subjects (Kimberg and D'Esposito, 2003; Muller et al, 1998) may be owing to different dosing and the nature of the learning paradigm. Previous studies only used single doses of pergolide, and the cognitive tasks probed working memory functions and not highly repetitive associative learning with long-term memory consolidation as in our study. Performance on day 1 was still at chance level $(<60 \%)$ for both the PERGOLIDE and the PLACEBO groups in our study (cf., Figure 2). So even if pergolide's tonic dopaminergic effects improve working memory functions, this was overcast probably by the task structure employed in our study. Probabilistic learning tasks over consecutive days seem to depend more on salience-coding (phasic dopamine signaling) than on working memory and attention (tonic dopamine modulation).

\section{Inhibition of Phasic Dopamine Signals through Tonic Activation of D2-Like Dopamine Autoreceptors}

Dopamine receptors are classified as D1-like ( $\mathrm{d} 1$ and $\mathrm{d} 5$ ) and D2-like (d2, d3, and $\mathrm{d} 4$ ) receptor subtypes, depending on their ability to either activate or inhibit adenylate cyclase (Jaber et al, 1996). Of the two receptor types, the postsynaptically located D1-like dopamine receptors are more abundant in learning-critical brain structures like the nucleus accumbens, the prefrontal cortex, and the hippocampus (Dailly et al, 2004). D2-like dopamine receptors are found both pre- and postsynaptically. The presynaptic D2like dopamine receptor subtype subserves most dopamine autoreceptor functions (Xu et al, 1999), including modulation of presynaptic synthesis and depolarization-evoked vesicular release of dopamine. This leads to a reduction in subsequent dopamine turnover, presumably as a means to control neural excitability levels (Mercier et al, 2001). The behavioral effect of this dopamine autoreceptor activation is most likely inhibitory because of the reduced phasic dopamine release into the synaptic cleft.

Pergolide is a mixed D1/D2-like dopamine agonist, with a high affinity for both pre- and postsynaptic D2-like receptors and lower affinity for postsynaptic D1 receptors (Miyagi et al, 1996). Low doses of D2-like receptor agonists have previously been shown to preferentially stimulate D2 autoreceptors (Tissari et al, 1983). An additional mechanism for the observed attenuation of vocabulary learning and slowed response times in our study is thus that the repeated administration of low doses of pergolide decreased presynaptic phasic dopamine release through a tonic activation of D2-like autoreceptors. However, because of the sparsity of mesocortical dopamine autoreceptors (White and Wang, 1984), this may not be the primary mechanism of pergolide's learning inhibition.

\section{D2-Receptor Dependent Inhibition of LTP in Learning-Critical Brain Structures}

Encoding of novel stimuli, like novel words, is meditated by synaptic plasticity in memory-relevant brain structures. The induction of LTP in glutamatergic neurons through intensive repetitive stimulation is important for long-term memory consolidation. The induction of LTP is critically 
modulated by endogenous dopaminergic input from midbrain neurons via the D1-receptor protein kinase A pathway to the hippocampus (Huang et al, 2004; Jay, 2003; Wittmann et al, 2005). The precise neuromodulatory mechanism of how dopamine receptors affect glutamate-dependent synaptic plasticity is not fully elucidated, but it has recently been shown that D1-like receptor stimulation modulates AMPA receptor synaptic insertion in glutamatergic neurons (Sun et al, 2005; Wolf et al, 2003). D2-like receptor stimulation, on the other hand, had the opposite effect by decreasing the production of synaptic insertion of AMPA receptors (Sun et al, 2005), presumably blocking LTP induction in learning-critical brain structures like the hippocampus. Pergolide's D2-like receptor-activating effect may have blocked the facilitating effect of (endogenous) D1receptor activation on LTP. This is in line with the observed impaired overall learning outcome of the PERGOLIDE group, suggesting a reduced efficiency of memory consolidation. This mechanism could be additive to the above mentioned scenarios of reduced phasic dopamine signaling by pergolide's tonic postsynaptic effects or through activation of dopamine autoreceptors by pergolide.

We would like to add in this context that the mixed mechanisms (D1-like mixed with D2-like auto- and heteroreceptor activation) should apply to all currently available dopamine agonists for humans as well as to levodopa. However, because levodopa improves associative learning despite its action on both D1- and D2-like receptors, the crucial difference between the effects of dopamine agonists and levodopa on learning seems to be levodopa's potential to increase the presynaptic availability of dopamine and thus to enhance phasic dopamine signals.

\section{ACKNOWLEDGEMENTS}

This work was supported by the Nachwuchsgruppe Kn2000 of the Nordrhein-Westfalen Ministry of Education and Research (Fö.1KS9604/0), the Interdisciplinary Center of Clinical Research Münster, Germany (IZKF Projects FG2 and Kne3/074/04), the Volkswagen Foundaton (Az.: I/80 708), an EC Marie Curie Research and Training Grant (RTN:LAB 512141), the German Ministry of Education and Research (BMBF: 01GW0520), and the Neuromedical Foundation Muenster, Germany. The funding organizations had no involvement in the study design. We are grateful to Ingrid Neuhaus (pharmacist) and Holger Sassenberg (student assistant) for their help with data acquisition.

\section{REFERENCES}

Antonini A, Schwarz J, Oertel WH, Beer HF, Madeja UD, Leenders $\mathrm{KL}(1994) .\left[{ }^{11} \mathrm{C}\right]$ raclopride and positron emission tomography in previously untreated patients with Parkinson's disease: influence of L-dopa and lisuride therapy on striatal dopamine D2receptors. Neurology 44: 1325-1329.

Baker SA, Baker KA, Hagg T (2004). Dopaminergic nigrostriatal projections regulate neural precursor proliferation in the adult mouse subventricular zone. Eur J Neurosci 20: 575-579.

Bartholomeusz CF, Box G, Van Rooy C, Nathan PJ (2003). The modulatory effects of dopamine D1 and D2 receptor function on object working memory in humans. J Psychopharmacol 17: 9-15.

Bitsios P, Giakoumaki SG, Frangou S (2005). The effects of dopamine agonists on prepulse inhibition in healthy men depend on baseline PPI values. Psychopharmacology (Berlin) 182: 1-9.

Bliss TV, Collingridge GL (1993). A synaptic model of memory: long-term potentiation in the hippocampus. Nature 361: 31-39.

Bragoni M, Altieri M, Di P, V Padovani A, Mostardini C, Lenzi GL (2000). Bromocriptine and speech therapy in non-fluent chronic aphasia after stroke. Neurol Sci 21: 19-22.

Breitenstein C, Jansen A, Deppe M, Foerster AF, Sommer J, Wolbers $\mathrm{T}$ et al (2005). Hippocampus activity differentiates good from poor learners of a novel lexicon. NeuroImage 25: 958-968.

Breitenstein C, Kamping S, Jansen A, Schomacher M, Knecht S (2004a). Word learning can be achieved without feedback: implications for aphasia therapy. Restor Neurol Neurosci 22: 445-458.

Breitenstein C, Knecht S (2002). Development and validation of a language learning model for behavioral and functional-imaging studies. J Neurosci Methods 114: 173-179.

Breitenstein C, Wailke S, Bushuven S, Kamping S, Zwitserlood P, Ringelstein EB et al (2004b). D-amphetamine boosts language learning independent of its cardiovascular and motor arousing effects. Neuropsychopharmacology 29: 1704-1714.

Castner SA, Goldman-Rakic PS (2004). Enhancement of working memory in aged monkeys by a sensitizing regimen of dopamine D1 receptor stimulation. J Neurosci 24: 1446-1450.

Cools R, Stefanova E, Barker RA, Robbins TW, Owen AM (2002). Dopaminergic modulation of high-level cognition in Parkinson's disease: the role of the prefrontal cortex revealed by PET. Brain 125: 584-594.

Curran MP, Perry CM (2004). Cabergoline: a review of its use in the treatment of Parkinson's disease. Drugs 64: 2125-2141.

Dailly E, Chenu F, Renard CE, Bourin M (2004). Dopamine, depression and antidepressants. Fundam Clin Pharmacol 18: 601-607.

Deppe M, Ringelstein EB, Knecht S (2004). The investigation of functional brain lateralization by transcranial Doppler sonography. NeuroImage 21: 1124-1146.

Ellis KA, Mehta MA, Wesnes KA, Armstrong S, Nathan PJ (2005). Combined D1/D2 receptor stimulation under conditions of dopamine depletion impairs spatial working memory performance in humans. Psychopharmacology (Berlin) 181: 1-10.

Fiorillo CD (2004). The uncertain nature of dopamine. Mol Psychiatry 9: 122-123.

Fiorillo CD, Tobler PN, Schultz W (2003). Discrete coding of reward probability and uncertainty by dopamine neurons. Science 299: 1898-1902.

Fiorillo CD, Tobler PN, Schultz W (2005). Evidence that the delayperiod activity of dopamine neurons corresponds to reward uncertainty rather than backpropagating TD errors. Behav Brain Funct 1: 7.

Floel A, Breitenstein C, Gaurraux G, Hummel F, Herscovitch P, Knecht S et al (2005a). Modulation von motorischer Gedächtnisbildung durch Levodopa [Modulation of motor memory formation by levodopa]. Akt Neurologie 32: S4.

Floel A, Breitenstein C, Hummel F, Celnik P, Gingert C, Sawaki L et al (2005b). Dopaminergic influences on formation of a motor memory. Ann Neurol 58: 121-130.

Floel A, Hummel F, Breitenstein C, Knecht S, Cohen LG (2005c). Dopaminergic effects on encoding of a motor memory in chronic stroke. Neurology 65: 472-474.

Gibbs SE, D'Esposito M (2005). A functional MRI study of the effects of bromocriptine, a dopamine receptor agonist, on component processes of working memory. Psychopharmacology (Berlin) 180: 644-653.

Gold M, VanDam D, Silliman ER (2000). An open-label trial of bromocriptine in nonfluent aphasia: a qualitative analysis of word storage and retrieval. Brain Lang 74: 141-156.

Goldman-Rakic PS, Muly III EC, Williams GV (2000). D(1) receptors in prefrontal cells and circuits. Brain Res Brain Res Rev 31: 295-301. 
Goto Y, Grace AA (2005). Dopaminergic modulation of limbic and cortical drive of nucleus accumbens in goal-directed behavior. Nat Neurosci 8: 805-812.

Grace AA (1991). Phasic versus tonic dopamine release and the modulation of dopamine system responsivity: a hypothesis for the etiology of schizophrenia. Neuroscience 41: 1-24.

Gupta SR, Mlcoch AG (1992). Bromocriptine treatment of nonfluent aphasia. Arch Phys Med Rehabil 73: 373-376.

Gupta SR, Mlcoch AG, Scolaro C, Moritz T (1995). Bromocriptine treatment of nonfluent aphasia. Neurology 45: 2170-2173.

Gurden H, Takita M, Jay TM (2000). Essential role of D1 but not D2 receptors in the NMDA receptor-dependent long-term potentiation at hippocampal-prefrontal cortex synapses in vivo. J Neurosci 20: RC106.

Haney M, Collins ED, Ward AS, Foltin RW, Fischman MW (1999). Effect of a selective dopamine D1 agonist (ABT-431) on smoked cocaine self-administration in humans. Psychopharmacology (Berlin) 143: 102-110.

Huang YY, Simpson E, Kellendonk C, Kandel ER (2004). Genetic evidence for the bidirectional modulation of synaptic plasticity in the prefrontal cortex by D1 receptors. Proc Natl Acad Sci USA 101: 3236-3241.

Jaber M, Robinson SW, Missale C, Caron MG (1996). Dopamine receptors and brain function. Neuropharmacology 35: 1503-1519.

Jankovic J (2002). Levodopa strengths and weaknesses. Neurology 58: $\mathrm{S} 19-\mathrm{S} 32$.

Jay TM (2003). Dopamine: a potential substrate for synaptic plasticity and memory mechanisms. Prog Neurobiol 69: 375-390.

Kandel ER (2001). The molecular biology of memory storage: a dialogue between genes and synapses. Science 294: 1030-1038.

Kimberg DY, D'Esposito M (2003). Cognitive effects of the dopamine receptor agonist pergolide. Neuropsychologia 41: $1020-1027$.

Kimberg DY, D'Esposito M, Farah MJ (1997). Effects of bromocriptine on human subjects depend on working memory capacity. NeuroReport 8: 3581-3585.

Knecht S, Breitenstein C, Bushuven S, Wailke S, Kamping S, Floel A et al (2004). Levodopa: faster and better word learning in normal humans. Ann Neurol 56: 20-26.

Koller WC, Rueda MG (1998). Mechanism of action of dopaminergic agents in Parkinson's disease. Neurology 50: S11-S14.

Korsukewitz C, Breitenstein C, Schomacher M, Knecht S (2006). Pharmakologische Zusatzbehandlung in der Aphasietherapie: status quo und Perspektiven. Nervenarzt 77: 403-415.

Kulisevsky J, Garcia-Sanchez C, Berthier ML, Barbanoj M, PascualSedano B, Gironell A et al (2000). Chronic effects of dopaminergic replacement on cognitive function in Parkinson's disease: a two-year follow-up study of previously untreated patients. Mov Disord 15: 613-626.

Lewis SJ, Slabosz A, Robbins TW, Barker RA, Owen AM (2005). Dopaminergic basis for deficits in working memory but not attentional set-shifting in Parkinson's disease. Neuropsychologia 43: 823-832.

Luciana M, Collins PF, Depue RA (1998). Opposing roles for dopamine and serotonin in the modulation of human spatial working memory functions. Cereb Cortex 8: 218-226.

Marie RM, Defer GL (2003). Working memory and dopamine: clinical and experimental clues. Curr Opin Neurol 16(Suppl 2): S29-S35.

Mattay VS, Goldberg TE, Fera F, Hariri AR, Tessitore A, Egan MF et al (2003). Catechol $O$-methyltransferase val158-met genotype and individual variation in the brain response to amphetamine. Proc Natl Acad Sci USA 100: 6186-6191.

Mattay VS, Tessitore A, Callicott JH, Bertolino A, Goldberg TE, Chase TN et al (2002). Dopaminergic modulation of cortical function in patients with Parkinson's disease. Ann Neurol 51: $156-164$
Mehta MA, Swainson R, Ogilvie AD, Sahakian J, Robbins TW (2001). Improved short-term spatial memory but impaired reversal learning following the dopamine $\mathrm{D}(2)$ agonist bromocriptine in human volunteers. Psychopharmacology (Berlin) 159: $10-20$.

Mercier D, Falardeau P, Levesque D (2001). Autoreceptor preference of dopamine D2 receptor agonists correlates with preferential coupling to cyclic AMP. NeuroReport 12: 1473-1479.

Miller JW, Selhub J, Nadeau MR, Thomas CA, Feldman RG, Wolf PA (2003). Effect of L-dopa on plasma homocysteine in PD patients: relationship to B-vitamin status. Neurology 60: 1125-1129.

Miyagi M, Itoh F, Taya F, Arai N, Isaji M, Kojima M et al (1996). Dopamine receptor affinities in vitro and stereotypic activities in vivo of cabergoline in rats. Biol Pharm Bull 19: 1210-1213.

Muller U, von Cramon DY, Pollmann S (1998). D1- versus D2-receptor modulation of visuospatial working memory in humans. J Neurosci 18: 2720-2728.

Nieoullon A (2002). Dopamine and the regulation of cognition and attention. Prog Neurobiol 67: 53-83.

Nutt JG, Fellman JH (1984). Pharmacokinetics of levodopa. Clin Neuropharmacol 7: 35-49.

Oldfield RC (1971). The assessment and analysis of handedness: the Edinburgh inventory. Neuropsychologia 9: 97-113.

Pahlke K, Scheidtmann K (2003). Levodopa steigert die Effektivität des Explorationstrainings bei linksseitigem Neglect [Levodopa boosts efficacy of exploration training after left-sided neglect]. Akt Neurol 30: S131.

Rascol O, Nutt JG, Blin O, Goetz CG, Trugman JM, Soubrouillard C et al (2001). Induction by dopamine D1 receptor agonist ABT431 of dyskinesia similar to levodopa in patients with Parkinson disease. Arch Neurol 58: 249-254.

Rinne JO, Rinne JK, Laakso K, Lonnberg P, Rinne UK (1985). Dopamine D-1 receptors in the parkinsonian brain. Brain Res 359: 306-310.

Robinson S, Sandstrom SM, Denenberg VH, Palmiter RD (2005). Distinguishing whether dopamine regulates liking, wanting, and/ or learning about rewards. Behav Neurosci 119: 5-15.

Roesch-Ely D, Scheffel H, Weiland S, Schwaninger M, Hundemer HP, Kolter T et al (2005). Differential dopaminergic modulation of executive control in healthy subjects. Psychopharmacology (Berlin) 178: 420-430.

Rogers JD, Sanchez-Saffon A, Frol AB, Diaz-Arrastia R (2003). Elevated plasma homocysteine levels in patients treated with levodopa: association with vascular disease. Arch Neurol 60: 59-64.

Sabe L, Leiguarda R, Starkstein SE (1992). An open-label trial of bromocriptine in nonfluent aphasia. Neurology 42: 1637-1638.

Sabe L, Salvarezza F, Garcia CA, Leiguarda R, Starkstein S (1995). A randomized, double-blind, placebo-controlled study of bromocriptine in nonfluent aphasia. Neurology 45: 2272-2274.

Scheidtmann K, Fries W, Muller F, Koenig E (2001). Effect of levodopa in combination with physiotherapy on functional motor recovery after stroke: a prospective, randomised, doubleblind study. Lancet 358: 787-790.

Schreckenberger $M$, Hagele $S$, Siessmeier T, Buchholz HG, Armbrust-Henrich H, Rosch F et al (2004). The dopamine D2 receptor ligand ${ }^{18} \mathrm{~F}$-desmethoxyfallypride: an appropriate fluorinated PET tracer for the differential diagnosis of parkinsonism. Eur J Nucl Med Mol Imaging 31: 1128-1135.

Schultz W (1994). Behavior-related activity of primate dopamine neurons. Rev Neurol (Paris) 150: 634-639.

Schultz W (1997). Dopamine neurons and their role in reward mechanisms. Curr Opin Neurobiol 7: 191-197.

Schultz W (2002). Getting formal with dopamine and reward. Neuron 36: 241-263.

Seshadri S, Beiser A, Selhub J, Jacques PF, Rosenberg IH, D’Agostino RB et al (2002). Plasma homocysteine as a risk 
factor for dementia and Alzheimer's disease. $N$ Engl J Med 346: 476-483.

Sulzer D, Sonders MS, Poulsen NW, Galli A (2005). Mechanisms of neurotransmitter release by amphetamines: a review. Prog Neurobiol 75: 406-433.

Sun X, Zhao Y, Wolf ME (2005). Dopamine receptor stimulation modulates AMPA receptor synaptic insertion in prefrontal cortex neurons. J Neurosci 25: 7342-7351.

Tissari AH, Rossetti ZL, Meloni M, Frau MI, Gessa GL (1983). Autoreceptors mediate the inhibition of dopamine synthesis by bromocriptine and lisuride in rats. Eur J Pharmacol 91: 463-468.

Tobler PN, Fiorillo CD, Schultz W (2005). Adaptive coding of reward value by dopamine neurons. Science 307: 1642-1645.

Waelti P, Dickinson A, Schultz W (2001). Dopamine responses comply with basic assumptions of formal learning theory. Nature 412: 43-48.

Watson D, Clark LA, Tellegen A (1988). Development and validation of brief measures of positive and negative affect: the PANAS scales. J Pers Soc Psychol 54: 1063-1070.

White FJ, Wang RY (1984). A10 dopamine neurons: role of autoreceptors in determining firing rate and sensitivity to dopamine agonists. Life Sci 34: 1161-1170.

Wittmann BC, Schott BH, Guderian S, Frey JU, Heinze HJ, Duzel E (2005). Reward-related FMRI activation of dopaminergic midbrain is associated with enhanced hippocampus-dependent long-term memory formation. Neuron 45: 459-467.

Wolf ME, Mangiavacchi S, Sun X (2003). Mechanisms by which dopamine receptors may influence synaptic plasticity. Ann NY Acad Sci 1003: 241-249.

Xu M, Koeltzow TE, Cooper DC, Tonegawa S, White FJ (1999). Dopamine D3 receptor mutant and wild-type mice exhibit identical responses to putative D3 receptor-selective agonists and antagonists. Synapse 31: 210-215. 